\title{
Historical reconstruction of background air pollution over France for 2000-2015
}

\author{
Elsa Real ${ }^{1}$, Florian Couvidat $^{1}$, Anthony Ung $^{1}$, Laure Malherbe $^{1}$, Blandine Raux $^{1}$, Augustin Colette $^{1}$ \\ ${ }^{1}$ INERIS, France \\ 5 Correspondence to: Elsa Real (elsa.real@ineris.fr)
}

\begin{abstract}
.
This paper describes a 16-year datasets of air pollution concentrations and air quality indicators over France. Using a kriging method that combines background measurements of air quality and modeling with the Chemistry Transport Model CHIMERE, hourly concentrations of $\mathrm{NO}_{2}, \mathrm{O}_{3}, \mathrm{PM}_{10}$ and $\mathrm{PM}_{2.5}$ are produced with a spatial resolution about 4 kilometers. Regulatory 10 indicators (annual average, SOMO35, AOT40 etc...) are also calculated from these hourly data. $\mathrm{NO}_{2}$ and $\mathrm{O}_{3}$ datasets cover the period 2000-2015, as well as $\mathrm{PM}_{10}$ annual data. $\mathrm{PM}_{10}$ hourly concentrations are not available from 2000 to 2007 due to known artefact in PM10 measurements. $\mathrm{PM}_{2.5}$ data are only available from 2009 because of the lack of measurement stations before. The overall dataset has been evaluated over all the years through a cross-validation process against background measurement stations (rural, sub-urban and urban), to account for the data fusion between measurement and models in the method. Results are very good for $\mathrm{PM}_{10}, \mathrm{PM}_{2.5}$ and $\mathrm{O}_{3}$. It shows an overestimation of $\mathrm{NO}_{2}$ concentrations in rural area, while background $\mathrm{NO}_{2}$ values in urban areas are well represented. Maps of the main indicators are shown over years and trends are calculated. Finally, country exposure and trends of three main health related indicators: yearly averaged $\mathrm{PM}_{2.5} \mathrm{NO}_{2}$ and SOMO35 are calculated. The DOI link for the dataset is http://doi.org/10.5281/zenodo.5043645 (Real et al., 2021). We hope that the publication of this dataset in open access will facilitate further studies on the impacts of air pollution.
\end{abstract}

\section{Introduction}

Air pollution is a major environmental risk for human health and ecosystems in Europe. During the last decades the European Union (EU) has put in place several measures to reduce anthropogenic emissions of pollutants. In response of emissions reductions, concentrations of $\mathrm{SO}_{2}, \mathrm{NO}_{2}$ and particles measured over Europe show a clear decrease (EEA, 2018). European background concentrations decreases have been recently evaluated by the EMEP Task Force on Measurements and Monitoring (TFMM) through analysis of measurements from the EMEP monitoring network (representatives of rural background concentrations) over the period 1990-2012 (EMEP, 2016).

Sulphur compounds show the largest decrease in response to strong sulfur emissions abatement. $\mathrm{NO}_{2}, \mathrm{NMVOC}$ and acidifying and eutrophying nitrogen pollutant emissions $\left(\mathrm{NOx}\right.$ and $\mathrm{NH}_{3}$ ) also decreased over the period 1990-2012 with reductions 
broadly consistent with the reported emission reductions in Europe for the same period. Decreases in $\mathrm{PM}_{10}$ and $\mathrm{PM}_{2.5}$ were also measured over the period 2002-2012. $\mathrm{O}_{3}$ trends are less straight forward despite decrease of its precursors. The magnitude of high ozone episodes has decreased whereas annual mean ozone levels measured at EMEP stations were increasing in the 1990s, and show a limited negative trend starting in 2002. This feature is generally attributed to the evolution of the global

5 baseline of tropospheric ozone for which further hemispheric control strategies are needed.

Based on methodologies established within EMEP, the trends in air pollution concentration for the period 2000-2010 have also been evaluated over France by the Laboratoire Central de Surveillance de la Qualité de l'Air (Malherbe et al, 2017) using observations with more diverse typologies (rural, urban, trafic ..). Significant reductions of $\mathrm{NO}_{2}$ and $\mathrm{PM}_{10}$ concentrations were also estimated over France for this period (-17\% and $-15 \%)$. The evolution is less favorable for ozone. Even if the peaks

10 decrease by $3.8 \%$ in amplitude, the averages increase by $5.5 \%$ over the period. Despite these reductions in pollutant emissions and pollutant concentrations (except for annual average $\mathrm{O}_{3}$ ), part of French citizens is still exposed to concentrations over the EU limit and target value and air quality in EU is still one of the main reasons of premature deaths (IHME, 2013).

Complementary to observations (that only gives partial spatial information), accurate, highly spatially resolved and up to date

15 maps of air pollution constitute an important information to assess air pollution trends and exposure. They are required to provide geographically detailed information on air pollutant concentration over the entire territory. These maps act as a basis for citizen information, for designing and stratifying monitoring networks and for supporting policy strategies and measuring their impact. They are also used to estimate population exposure to air pollutants, essential to epidemiological studies.

At European scale, different mapping approaches have been used to produce maps of pollutant concentrations. These maps can be obtained by modeling using a regional Chemistry Transport Model (CTM) that simulates concentration of pollutants over Europe. However, these models cannot always be used over all Europe with a high resolution and present some biases and spatial representativity limitations. Regression methods (Briggs et al., 2000; Beelen et al., 2007) are also used at different scale. These stochastic modelling techniques develop statistical associations between potential 'predictor variables' (land use, emission sources, topography) and measured pollutant concentrations, to predict concentration at unsampled site. Other techniques frequently used are kriging techniques. These geostatistical techniques are based on the hypothesis that the data are spatially autocorrelated, and so take into account the distances between measurements and the spatial structure of the variable. Different types of kriging are used to map air pollutant concentration. Over France, kriging methods that combine information from a regional CTM (CHIMERE, (Mailler et al., 2017)) and observations are produced daily by the Operational Forecasting

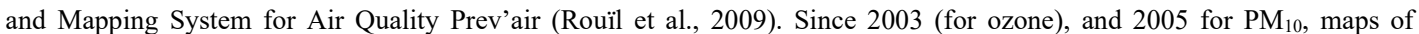
concentrations simulated for the day before in Prev'air are corrected each morning using observations. The kriging technique used in Prev'Air has evolved in time, and $\mathrm{PM}_{2.5}$ and $\mathrm{NO}_{2}$ concentrations are now also corrected for the day before. Today, an hourly observations kriging with CHIMERE as an external drift is applied to map $\mathrm{NO}_{2}$ and $\mathrm{O}_{3}$ concentrations. Since 2017, for 
the mapping of $\mathrm{PM}_{10}$ and $\mathrm{PM}_{2.5}$ concentrations, the method used is an hourly cokriging of $\mathrm{PM}_{10}$ and $\mathrm{PM}_{2.5}$ data with CHIMERE in external drift. These choices are the results of successive studies that compared different kriging techniques (Malherbe and Ung, 2009, Beauchamp 2015a).

The purpose of this paper and its associated datasets is to present and provide $\mathrm{O}_{3}, \mathrm{NO}_{2}, \mathrm{PM}_{10}$ and $\mathrm{PM}_{2.5}$ concentration mapped

5 data with high spatial and temporal resolution as well as associated regulatory indicators covering the French metropolitan territory for the period 2000-2015 (2007-2015 and 2009-2015 for hourly $\mathrm{PM}_{10}$ and $\mathrm{PM}_{2.5}$ concentrations). The same kriging technique as in the Prev'air system is used to combine modeling and observed concentrations. Hourly concentrations of $\mathrm{PM}_{10}$, $\mathrm{PM}_{2.5}, \mathrm{NO}_{2}$ and $\mathrm{O}_{3}$ are produced and mapped over France and these hourly data are then used to calculate and map Air Quality European and French standards.

\section{Methods}

Model outputs and measurements from the permanent monitoring network were combined by external drift kriging (Malherbe and Ung, 2009; Benmerad et al., 2017) to build hourly concentration maps over France for a long-time period: 2000 to 2015. Details on input data and methods used are described in the following paragraphs. Using these corrected hourly concentration data, maps of annual regulatory air quality indicators are subsequently derived over France.

\subsection{Monitoring data}

Hourly measurement are extracted from reference sets of validated data. Over France, observations are extracted from the national air quality databases: BDQA (Base de Données de Qualité de l'Air) before 2013 and GEODAIR (https://www.lcsqa.org/fr/les-donnees-nationales-de-qualite-de-lair) after 2013; and from the Airbase database (https://www.eea.europa.eu/themes/air/air-quality/map/airbase) for other European countries from 2000 to 2012 and AQ ereporting (https://www.eea.europa.eu/data-and-maps/data/aqereporting-8/aq-ereporting-products) from 2013 to 2015. All background monitoring data over the spatial domain are used in the kriging procedure, except for stations with measurements exceeding the 95 percentiles. This includes rural, suburban and urban stations but excludes industrial and traffic stations that are representative of very local concentration, hardly reproducible within a nation-wide mapping system. The number of background monitoring sites for each type of stations and for each year are summarize in Table 1.

Table 1: Number of background French monitoring sites for the years 2000 to 2015

\begin{tabular}{|l|l|l|l|l|l|l|l|l|l|l|l|l|l|l|l|l|}
\hline & 2000 & 2001 & 2002 & 2003 & 2004 & 2005 & 2006 & 2007 & 2008 & 2009 & 2010 & 2011 & 2012 & 2013 & 2014 & 2015 \\
\hline $\mathrm{O}_{3}$ & 284 & 310 & 337 & 362 & 378 & 396 & 404 & 405 & 399 & 385 & 376 & 360 & 347 & 318 & 319 & 331 \\
\hline $\mathrm{NO}_{2}$ & 274 & 290 & 299 & 322 & 337 & 353 & 353 & 350 & 352 & 337 & 334 & 316 & 299 & 284 & 282 & 300 \\
\hline $\mathrm{PM}_{10}$ & 119 & 125 & 171 & 212 & 219 & 238 & 126 & 219 & 252 & 241 & 249 & 245 & 240 & 218 & 173 & 251 \\
\hline $\mathrm{PM}_{2.5}$ & 3 & 7 & 18 & 22 & 25 & 32 & 38 & 6 & 28 & 62 & 69 & 74 & 84 & 89 & 90 & 105 \\
\hline
\end{tabular}


Because $\mathrm{PM}_{2.5}$ measurements stations were scarce in France before 2009, $\mathrm{PM}_{2.5}$ mapped data will only be computed for the period 2009-2015. Also, until 1 January 2007, operational monitoring of $\mathrm{PM}_{10}$ and $\mathrm{PM}_{2.5}$ was carried out in France by automatic measuring systems of the TEOM $\left(\mathrm{PM}_{10}, \mathrm{PM}_{2.5}\right)$ or Beta $\left(\mathrm{PM}_{10}\right)$ type. However, compared to the reference method EN 12341

5 (gravimetry), these systems underestimate the concentrations of $\mathrm{PM}_{10}$. This is a known artefact related to the loss of semivolatile compounds. To correct $\mathrm{PM}_{10}$ measured concentrations before 2007, a simple approach consists in applying a uniform correcting factor over France. This method is not adapted for a correction of hourly or daily concentrations, but it has been shown to give good results for yearly mean $\mathrm{PM}_{10}$ concentrations (Malherbe et al., 2017, Bessagnet et al., 2008). The factor (1.36) is a median value calculated on the $\mathrm{PM}_{10}$ data from "reference" sites (Bessagnet et al., 2008). As a consequence, for the

10 period 2000 to 2006 , the only $\mathrm{PM}_{10}$ indicator available is the annual mean concentration.

\subsection{CHIMERE simulations}

The CHIMERE chemistry-transport model (Couvidat et al., 2018) is used to estimate air pollution levels for the metropolitan France, with a resolution of approximately $4 \mathrm{~km}$ resolution $\left(0.06^{\circ} \times 0.03^{\circ}\right)$ over the year 2000 to 2015 . This model has long

15 been implemented and assessed in France as the main component of the national air quality forecasting and monitoring system PREV'AIR (Honoré et al., 2008). Two types of input data are used to simulate the concentrations.

Prior to 2010, a setup similar to the one use in the EURODELTA-Trends project (Colette et al., 2017) is used. The methodology of Colette et al. (2017) is used to reconstruct the emissions of main air pollutants (Non Methanic Volatile Organic Compound (NMVOC), $\mathrm{NOx}, \mathrm{CO}, \mathrm{SO}_{2}, \mathrm{NH}_{3}$, and Primary $\mathrm{PM}$ ): the annual emissions of every countries, distributed by SNAP

20 (Selected Nomenclature for reporting of Air Pollutants) sectors, are estimated with the GAINS (Greenhouse gases and Air pollution Interactions and Synergies) model (Amann et al., 2011) for the years 2000, 2005, and 2010 . To derive emissions for intermediate years, sectorial results for 5-year periods are linearly interpolated. Meteorological data are simulated with the Weather Research and Forecast Model (WRF version 3.3.1; Skamarock et al., 2008) from 2000 to 2010.

For the period 2011 to 2015, year-to-year emissions of the main pollutants are issued from EMEP (Cooperative programme 25 for monitoring and evaluation of long range transmission of air pollutants in Europe) programme available at http://www.emep.int. Year-to-year meteorological data were provided by ECMWF with the Integrated Forecasting System (IFS) model with data assimilation.

For these two datasets, the spatialization of emissions over France is performed with a $1 \mathrm{~km}$ proxy based on the national bottom-up emission inventory (available at http://emissions-air.developpement-durable.gouv.fr/) that feeds the emission pre-

30 processor of CHIMERE described in Mailler et al. (2017). Moreover, Denier van der Gon et al. (2015) showed that emissions of primary particles from residential wood burning can be underestimated up to a factor 2-3 over Europe because emissions 
are lacking a large part semivolatile compounds. To compensate this underestimation, a factor of correction by countries determined from Denier van der Gon et al. (2015) is applied over the whole period.

\subsection{Kriging}

5 Hourly atmospheric concentration fields are estimated by external drift kriging, combining surface monitoring observations and outputs from the CHIMERE chemistry transport model. European stations outside the French domain are included in the kriging to increase accuracy at the borders. Kriging is performed using a moving neighbourhood as this allows local adjustment of the relationship between measurements and CHIMERE. Concentration at each grid point is estimated within a window of 80 monitoring sites. This number was adjusted in previous studies by sensitivity tests (Benmerad et al., 2017; Beauchamp et

10 al., 2017). In addition, a smoothing is applied to avoid discontinuities in the map (Beauchamp et al., 2015b); the smoothing methodology was adapted from Rivoirard and Romary (2011). The final output resolution is the same as for the CHIMERE model: approximately $4 \mathrm{~km}$ resolution $\left(0.06^{\circ} \times 0.03^{\circ}\right)$.

For particles $\left(\mathrm{PM}_{10}\right.$ and $\left.\mathrm{PM}_{2.5}\right)$ a co-kriging with external drift is applied to take into account the correlation between $\mathrm{PM}_{10}$ (particles with a radius $<10 \mu \mathrm{m}$ ) and $\mathrm{PM}_{2.5}$ (particles with a radius $<2.5 \mu \mathrm{m}$ ) and improve consistency between $\mathrm{PM}_{10}$ and

$15 \mathrm{PM}_{2.5}$ estimates (Beauchamp et al., 2015b). Such cokriging also allows $\mathrm{PM}_{2.5}$ estimation to benefit from the higher density of $\mathrm{PM}_{10}$ monitoring stations.

\subsection{Output: regulatory air quality indicators}

From the kriged hourly concentrations, several air quality indicators (regulatory and used in health impact assessment) are calculated and mapped over France. The complete list and definition of these indicators are given in Table 2.

20

Table 2: Yearly regulatory air quality indicators from EU legislation or French legislation and usual indicators.

\begin{tabular}{|l|c|l|l|l|l|}
\hline ID & Pollutant & \multicolumn{1}{|c|}{ Statistics } & \multicolumn{1}{|c|}{ Threshold } & Threshold origin & Target to protect \\
\hline NO2_avgannual & NO2 & Yearly average & $40 \mu \mathrm{g} \cdot \mathrm{m}^{-3}$ & Limit value (EU) & Human health \\
\hline O3_avgannual & O3 & Yearly average & & & \\
\hline O3_AOT40 & O3 & $\begin{array}{l}\text { AOT40* from May to } \\
\text { July }\end{array}$ & $6000 \mu \mathrm{g} \cdot \mathrm{m}^{-3}$ & $\begin{array}{l}\text { Long-term } \\
\text { objective }\end{array}$ & Vegetation \\
\hline O3_AOT40_5years & O3 & $\begin{array}{l}\text { AOT40* from May to } \\
\text { July (5 years average) }\end{array}$ & $18000 \mu \mathrm{g} \cdot \mathrm{m}^{-3}$ & Target value (EU) & Vegetation \\
\hline O3_SOMO35 & O3 & $\begin{array}{l}\text { Sum of excess of max } \\
\text { daily 8-hour averages } \\
\left.\text { over 35 ppb (=70 } \mu \mathrm{g} \mathrm{m}^{-3}\right) \\
\text { calculated for all days in a } \\
\text { year; SOMO35 (Sum Of } \\
\text { Means Over 35 ppb) }\end{array}$ & Health Impact & Human health \\
\hline
\end{tabular}




\begin{tabular}{|c|c|c|c|c|c|}
\hline O3_T120 & $\mathrm{O} 3$ & $\begin{array}{l}\text { Number of days for } \\
\text { which the running } \\
\text { average over } 8 \mathrm{~h} \text { exceeds } \\
120 \mu \mathrm{g} \cdot \mathrm{m}^{-3}\end{array}$ & & $\begin{array}{l}\text { Quality objective } \\
\text { (EU) }\end{array}$ & Human health \\
\hline O3_T120_3years & $\mathrm{O} 3$ & $\begin{array}{l}\text { Number of days for } \\
\text { which the running } 8 \mathrm{~h} \\
\text { average exceeds } 120 \\
\mu \mathrm{g} . \mathrm{m}^{-3} \text { (averaged over } 3 \\
\text { years) }\end{array}$ & $\begin{array}{l}\text { Not to exceed } \\
\text { more than } 25 \\
\text { days a year }\end{array}$ & Target value (EU) & Human health \\
\hline O3_T180 & $\mathrm{O} 3$ & $\begin{array}{l}\text { Number of hours } \\
\text { exceeding the average } \\
\text { value of } 180 \mu \mathrm{g} \cdot \mathrm{m}^{-3}\end{array}$ & & $\begin{array}{l}\text { Recommendation } \\
\text { and Information } \\
\text { Threshold } \\
\text { (France) }\end{array}$ & Human health \\
\hline O3_T240 & $\mathrm{O} 3$ & $\begin{array}{l}\text { Number of hours } \\
\text { exceeding the average } \\
\text { value of } 240 \mu \mathrm{g} \cdot \mathrm{m}^{-3}\end{array}$ & & $\begin{array}{l}\text { Alert threshold } \\
\text { (France) }\end{array}$ & Human health \\
\hline PM10_avgannual & PM10 & Yearly average & $40 \mu \mathrm{g} \cdot \mathrm{m}^{-3}$ & Limit value (EU) & Human health \\
\hline PM10_t50 & PM10 & $\begin{array}{l}\text { Number of days } \\
\text { exceeding the average } \\
\text { value of } 50 \mu \mathrm{g} \cdot \mathrm{m}^{-3}\end{array}$ & $\begin{array}{l}\text { Not to exceed } \\
\text { more than } 35 \\
\text { days a year }\end{array}$ & Limit value (EU) & Human health \\
\hline PM10_t80 & PM10 & $\begin{array}{l}\text { Number of days } \\
\text { exceeding the average } \\
\text { value of } 80 \mu \mathrm{g} \cdot \mathrm{m}^{-3}\end{array}$ & & $\begin{array}{l}\text { Alert threshold } \\
\text { (France)) }\end{array}$ & Human health \\
\hline PM25 avgannual & PM25 & Yearly average & $25 \mu \mathrm{g} \cdot \mathrm{m}^{-3}$ & Limit value (EU) & Human health \\
\hline
\end{tabular}

*AOT 40 (expressed in $\mu \mathrm{g} / \mathrm{m}^{3}$.hour) means the sum of differences between hourly concentrations greater than $80 \mu \mathrm{g} / \mathrm{m}^{3}(=$ $40 \mathrm{ppb}$ or part per billion) and $80 \mu \mathrm{g} / \mathrm{m}^{3}$ for a given period using only the values 1 hour measured daily between 8 am and 8 pm.

\section{Data validation}

5 Usually the quality of estimated concentrations maps is assessed using statistical indicators that compare observations and estimated concentrations at the monitoring stations over the domain. Here, information of all background stations over the domain are already used to develop the maps. Therefore, for a fair comparison, cross-validation method is used. The crossvalidation method computes the quality of the spatial interpolation for each measurement station point from all available information except from the selected station point, i.e. it withholds one data point and then makes a prediction at the spatial

10 location of that point. This procedure is repeated for all measurement points in the available set, enabling the evaluation of the quality of the predicted values at locations without measurements (as long as they are within the area covered by the measurements).

It has been noticed that scores are systematically different over rural or urban stations (even if the kriging technique used here is not differentiate by type of station). Therefore, the results of the cross-validation are described per pollutant and 15 differentiated type of stations (rural and urban types are shown here). Three statistical indicators are calculated based on daily 
mean concentration: the mean bias, the root mean squared error (RMSE) and the pearson correlation (r). For each year, they are first calculated over the "left out" station and then the median values over all stations are calculated.

\subsection{4. $\quad \mathbf{P M}_{10}$}

(a)

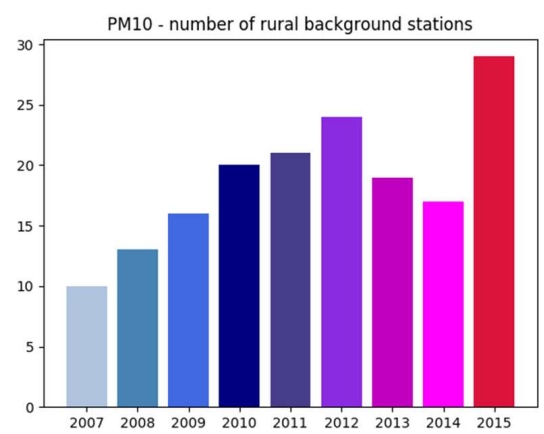

(b)

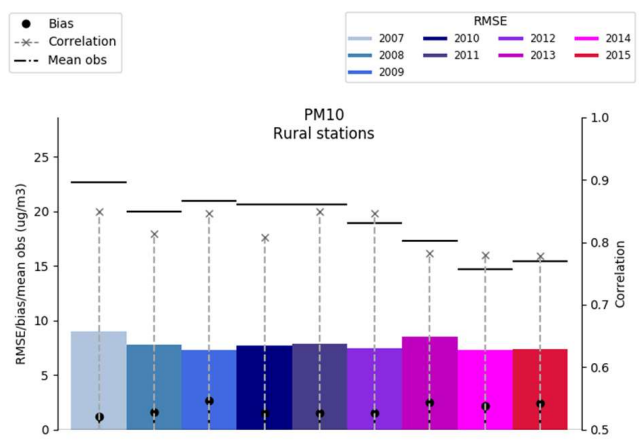

5

Figure 1: $P M_{10}$ : statistical indicators calculated using cross-validation technique on daily mean PM10 values measured and estimated over RURAL background stations for the years 2007 to 2015. (a) number of rural stations for each year; (b) mean bias (black circles), RMSE (coloured rectangles), correlation (grey crosses) and mean observation (horizontal lines).

(a)

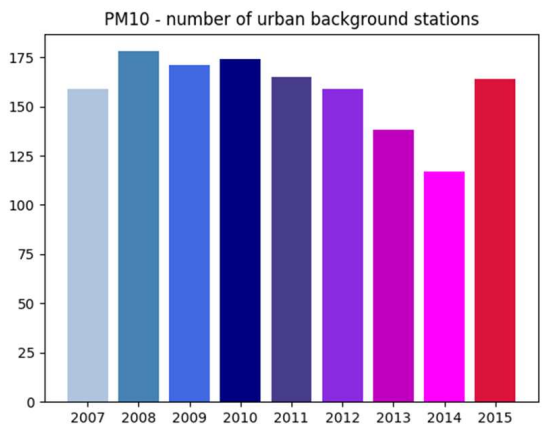

(b)

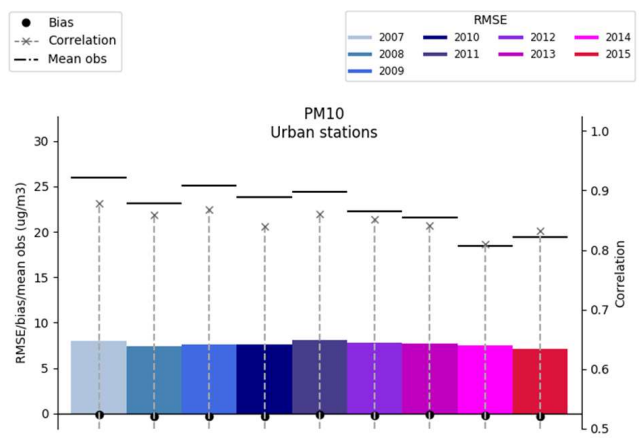

Figure 2: PM10: statistical indicators calculated using cross-validation technique on daily mean $P_{10}$ values measured and estimated over URBAN background stations for the years 2007 to 2015. (a) number of rural stations for each year. (b) Bias (black circles), RMSE (coloured rectangles), correlation (grey crosses) and mean observation (horizontal lines) 
The scores show an overall good representation of the observations by the reanalysed data with correlations between 0.77 and 0.86 and RMSE around $7 \mu \mathrm{g} \cdot \mathrm{m}^{-3}$, i.e between $30 \%$ and $50 \%$ of the mean yearly PM10 concentration. The mean biases are particularly low for urban stations with values smaller than $-1 \%$. For rural stations the mean bias lies below $+3 \mu \mathrm{g} . \mathrm{m}^{-3}$, i.e

5 below $+15 \%$. The proportion between rural and urban stations varies between $1 / 3$ and $1 / 10$. The larger number of urban stations leads to a better capture of the spatial variability of concentrations in urban environments.

Looking at the evolution of scores over the years, for rural stations, the number of stations available first increase from 2009 to 2012 before a decrease up to 2014. In 2015 a new increase starts in the number of stations over France. For urban stations, the decrease starts earlier (2010) but the evolution is the same. The temporal evolution of the scores generally follows the number of stations with higher correlations and smaller relative mean biases and RMSE when more stations are available. Indeed the largest is the number of stations, the more representative of the real spatial variability will be the kriging technique. There are however exceptions as shown in 2015 for rural stations, with the second worst scores whereas that year has the largest number of stations.

\subsection{5. $\quad \mathrm{PM}_{2.5}$}

(a)

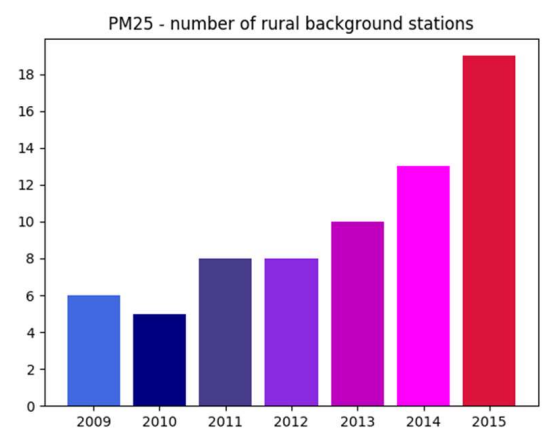

(b)

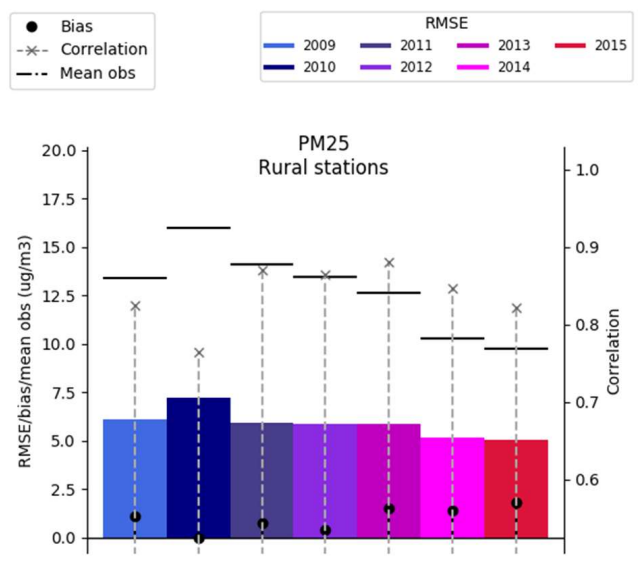


Figure 3: $\mathrm{PM}_{2.5}$ : statistical indicators calculated using cross-validation technique on daily mean $\mathbf{P M}_{2.5}$ values measured and estimated over RURAL background stations for the years 2009 to 2015. (a) number of rural stations for each year. (b) Bias (black circles), RMSE (coloured rectangles), correlation (grey crosses) and mean observation (horizontal lines)

(a)

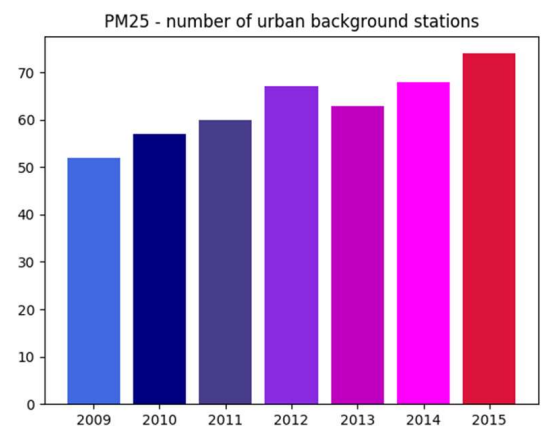

(b)

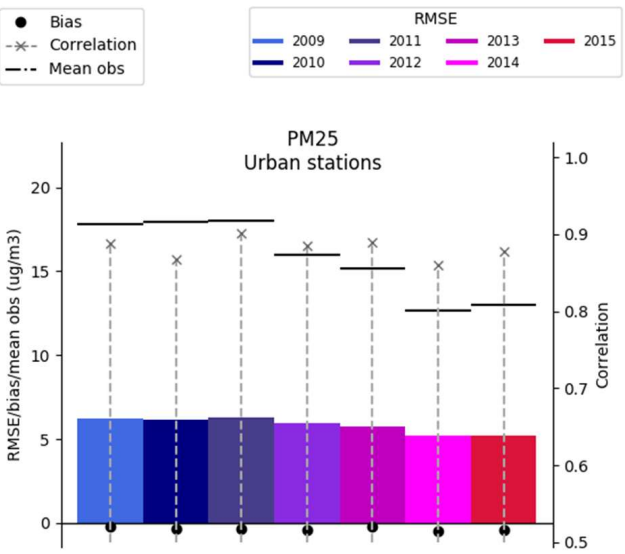

Figure 4: $\mathrm{PM}_{2.5}$ : statistical indicators calculated using cross-validation technique on daily mean $\mathbf{P M}_{2.5}$ values measured and estimated over URBAN background stations for the years 2009 to 2015. (a) number of rural stations for each year. (b) Bias (black circles), RMSE (coloured rectangles), correlation (grey crosses) and mean observation (dotted horizontal lines)

There is between one half to one third less $\mathrm{PM}_{2.5}$ than $\mathrm{PM}_{10}$ stations. However, thanks to the use of a co-kriging technique, the mapping for $\mathrm{PM}_{2.5}$ also benefits from $\mathrm{PM}_{10}$ information, so that correlations, mean bias and RMSE are almost similar to $\mathrm{PM}_{10}$ scores. Mean biases for rural stations do not exceed $20 \%$ of the mean concentrations and is very low for urban stations (between 0 and $-3 \%$ ). As for $\mathrm{PM}_{10}$, this bias is systematically positive over rural station (overestimation) and slightly negative over urban ones (underestimation). This mainly has to do with data resolution that smooth out concentration gradients, giving unique value over each grid (around $4 \mathrm{~km}$ horizontal resolution). For urban station, located close to $\mathrm{PM}_{2.5}$ precursor emissions and usually showing high concentration values, this smoothing effect results in underestimation. Over rural areas located far from emission precursors, the opposite is observed.

Correlation is usually higher than 0.8 and RMSE do not exceed $7 \mu \mathrm{g} \cdot \mathrm{m}^{-3}$ (at maxima $50 \%$ of the mean yearly concentration). 
https://doi.org/10.5194/essd-2021-182

Preprint. Discussion started: 13 July 2021

(c) Author(s) 2021. CC BY 4.0 License.

(a)

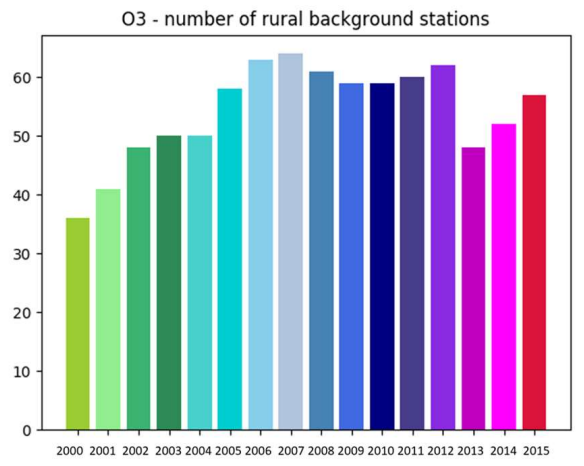

(b)

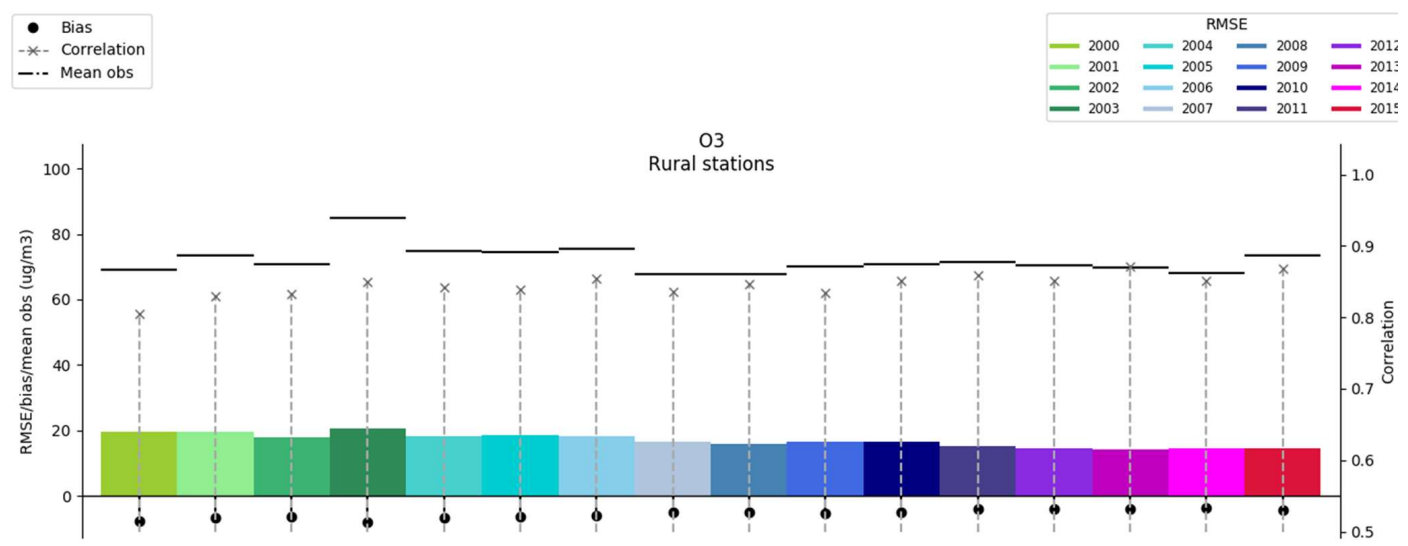

Figure 5: $\mathrm{O}_{3}$ : statistical indicators calculated using cross-validation technique on daily mean $\mathrm{O}_{3}$ values measured and estimated over RURAL background stations for the years 2000 to 2015. (a) number of rural stations for each year. (b) Bias (black circles), RMSE (coloured rectangles), correlation (grey crosses) and mean observation (horizontal lines)

Comparison between estimated and observed ozone on rural stations show good correlations ( 0.8 to 0.87$)$, small relative mean negative biases (-4 to $-8 \%$ ) and low RMSE (around $20 \%$ of the yearly average concentration). Between 2000 and 2007 the 
number of rural stations increased resulting in an improvement of the modelled concentration maps. The small decrease in the number of stations after 2007 do not penalize the scores for these years.

(a)

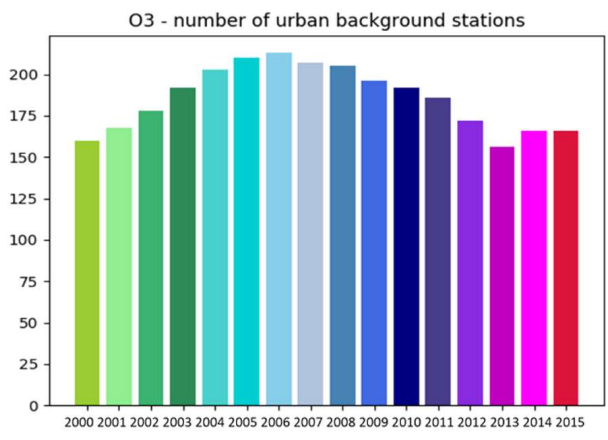

(b)

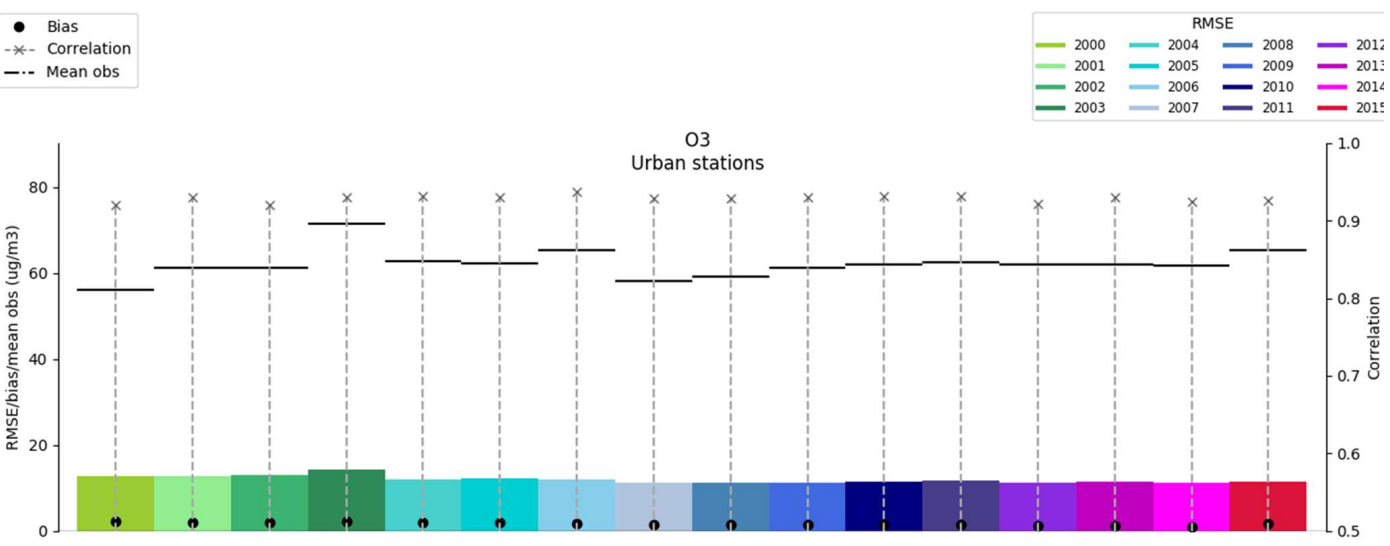

5 Figure 6: $\mathrm{O}_{3}$ : statistical indicators calculated using cross-validation technique on daily mean $\mathrm{O}_{3}$ values measured and estimated over URBAN background stations for the years 2000 to 2015. (a) number of urban stations for each year. (b) Bias (black circles), RMSE (coloured rectangles), correlation (grey crosses) and mean observation (horizontal lines)

The same conclusions can be drawn for urban ozone scores. The higher number of urban stations leads even to slightly better scores with correlations over 0.9 for all years and relative mean positive biases that do not exceed $5 \%$. A satisfactory RMSE

10 is also obtained for all years with values around $20 \%$ of the yearly mean concentration. It can be noticed that the positive and 
https://doi.org/10.5194/essd-2021-182

Preprint. Discussion started: 13 July 2021

(c) Author(s) 2021. CC BY 4.0 License.

negative bias is inverted compared to scores of PM. Indeed, larger value of $\mathrm{O}_{3}$ are usually observed over rural areas when precursors had time to produce $\mathrm{O}_{3}$ and where $\mathrm{O}_{3}$ destruction is lowest than in urban environment. Therefore, the smoothing effect has the opposite effect as for PM.

(a)

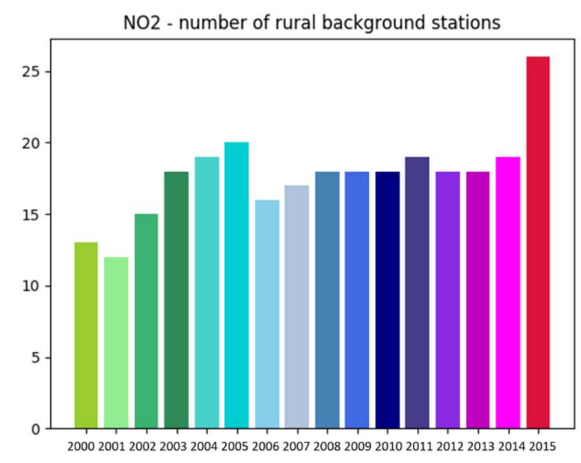

(b)

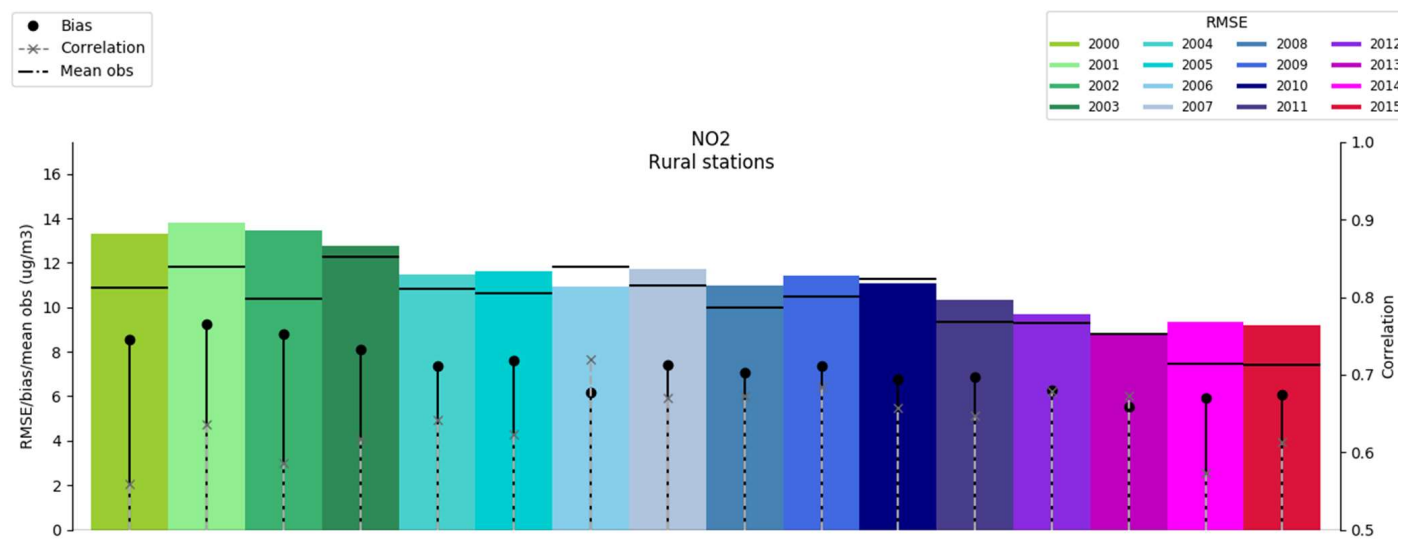


https://doi.org/10.5194/essd-2021-182

Preprint. Discussion started: 13 July 2021

(c) Author(s) 2021. CC BY 4.0 License.

Figure 7: $\mathrm{NO}_{2}$ : statistical indicators calculated using cross-validation technique on daily mean $\mathrm{NO}_{2}$ values measured and estimated over RURAL background stations for the years 2000 to 2015. (a) number of rural stations for each year. (b) Bias (black circles), RMSE (coloured rectangles), correlation (grey crosses) and mean observation (horizontal lines)

$\mathrm{NO}_{2}$ rural scores are worse than for particles or $\mathrm{O}_{3}$. Correlations stands between 0.55 and 0.7 but more importantly, strong

5 positive biases are found for all years with an overestimation of the observations by a 60 to $80 \%$. This also affects RMSE scores that can exceed $100 \%$ of the yearly mean concentration. These low performances can be explained by the strong spatial gradients of $\mathrm{NO}_{2}$ concentrations due to its lower atmospheric lifetime than $\mathrm{O}_{3}$ or particles. There are too few rural stations to correctly catch this variability in the kriging technique used here so that urban stations have too much of a large weight, and the raw model concentrations also overestimate the rural concentrations.

(a)

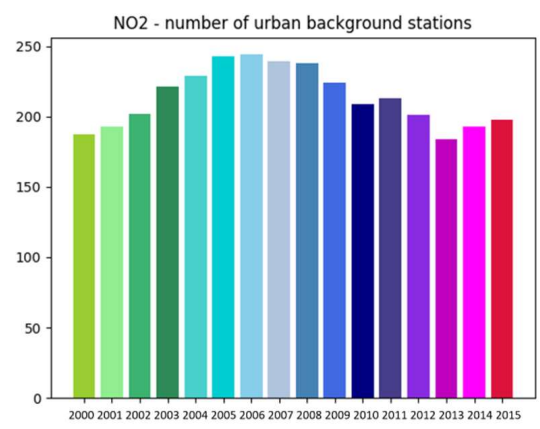

(b) 


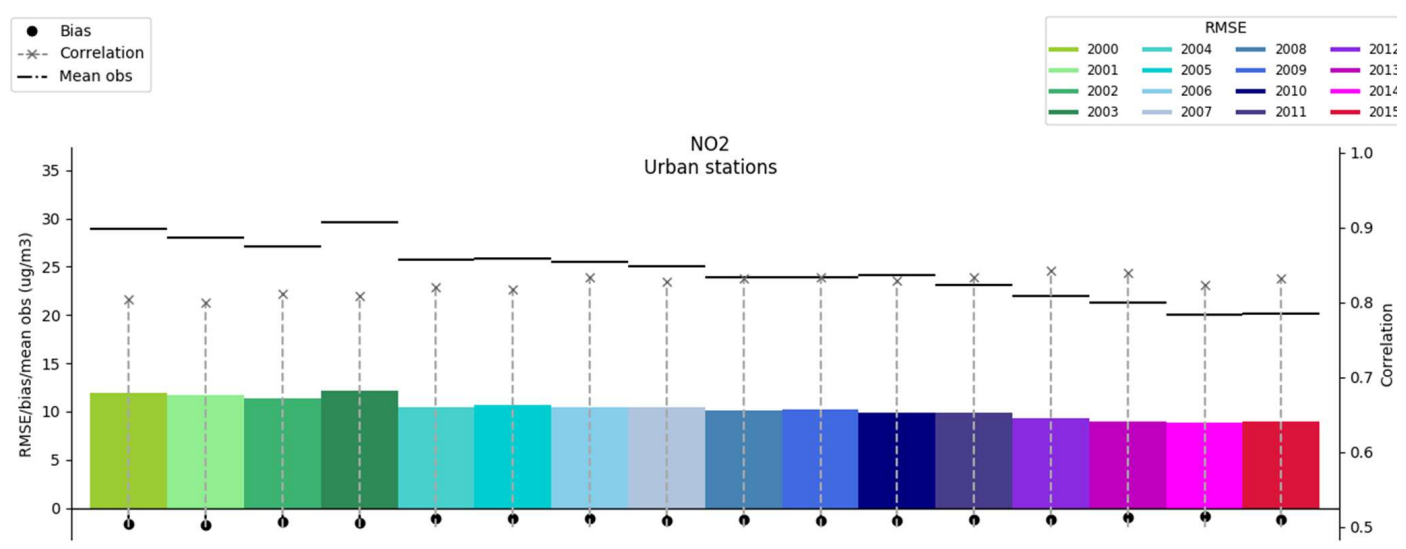

Figure 8: $\mathrm{NO}_{2}$ : statistical indicators calculated using cross-validation technique on daily mean $\mathrm{NO}_{2}$ values measured and estimated over URBAN background stations for the years 2000 to 2015. (a) number of urban stations for each year. (b) Bias (black circles), RMSE (coloured rectangles), correlation (grey crosses) and mean observation (horizontal lines)

5 Urban scores for $\mathrm{NO}_{2}$ are much better than rural ones. Correlations evolve around 0.8, biases do not exceed $-3.5 \%$ and RMSE stand between 10 to $12 \mu \mathrm{g} \cdot \mathrm{m}^{-3}$ (lower than $25 \%$ of the yearly mean concentration). The high number of urban background stations seems satisfactory to allow the kriging technique to correctly reproduce the $\mathrm{NO}_{2}$ spatial variability in urban background environments. It should be noted however that traffic stations are not used in the present reanalysis.

10 Overall, these cross-validations show a good representation of background measurements of $\mathrm{O}_{3}, \mathrm{PM}_{10}, \mathrm{PM}_{2.5}$ and $\mathrm{NO}_{2}$ over France, except for rural $\mathrm{NO}_{2}$ concentration that are overestimated. From this base, yearly indicators, trend over years and human exposition were calculated.

\section{Results}

Hourly concentrations fields are calculated from 2000 to 2015 for $\mathrm{NO}_{2}, \mathrm{O}_{3}$ and $\mathrm{PM}_{10}$, however, as explain in section 2, for

$15 \mathrm{PM}_{10}$ only annual mean indicators maps are produced before 2007. $\mathrm{PM}_{2.5}$ hourly concentrations are calculated for year 2009 to 2015 due to the lack of background stations before 2009 .

\subsection{Concentration maps and trends}

All indicators given in section 2 are calculated but the following section focus on averaged annual mean concentrations of $\mathrm{PM}_{10}, \mathrm{PM}_{2.5}, \mathrm{NO}_{2}$ and $\mathrm{O}_{3}$, as well as SOMO35 and AOT (two indicators associated to $\mathrm{O}_{3}$ ), for which mapped data are shown. 
Trend analyse over the period is performed by calculating the Sen-Theil regression slope for each grid point over the domain. To characterize the significance of these trend slopes, the $95 \%$ confidence interval This confidence interval represents the lower and upper values above or below which you are confident (at $95 \%$ ) that the trends will occur. The smaller the confidence interval, the more statistically significant the trend. Large confidence intervals are considered as unrepresentative, especially

5 those containing 0 . Trend slopes and confidence intervals are calculated over the domain but country averaged values are also given in Table 3.

Table 3: country averaged slope and its $95 \%$ confidence interval

\begin{tabular}{|l|l|l|}
\hline Indicator & $\begin{array}{l}\text { Mean tendency slope (or } \\
\text { mean trend) in } \mu \mathrm{g} . \mathrm{m}^{-3} \cdot \mathrm{year}^{-1}\end{array}$ & $\begin{array}{l}\text { Mean 95 \% confidence } \\
\text { interval }\left(\mathrm{in} \mu \mathrm{g} \cdot \mathrm{m}^{-3} \cdot \mathrm{year}^{-1}\right)\end{array}$ \\
\hline $\mathrm{PM}_{10}$ - avg annual & -0.8 & {$[-0.5 ;-1.09]$} \\
\hline $\mathrm{PM}_{2.5}$ - avg annual & -0.87 & {$[-0.48 ;-1.41]$} \\
\hline $\mathrm{O}_{3}$ - avg annual & 0.32 & {$[0.005 ; 0.59]$} \\
\hline $\mathrm{O}_{3}-\mathrm{SOMO} 55$ & -5.52 & {$[-102.7 ; 76.7]$} \\
\hline $\mathrm{O}_{3}-\mathrm{AOT}$ & -142 & {$[-641 ; 315]$} \\
\hline $\mathrm{NO}_{2}-$ avg annual & -0.32 & {$[-0.3 ;-0.63]$} \\
\hline & & \\
\hline
\end{tabular}

\subsection{1. $\quad \mathrm{PM}_{10}$}

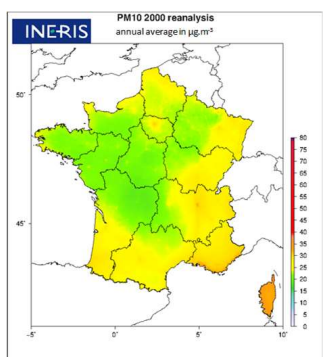

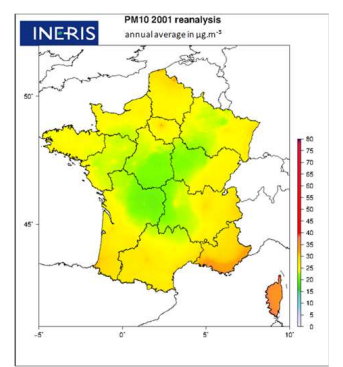
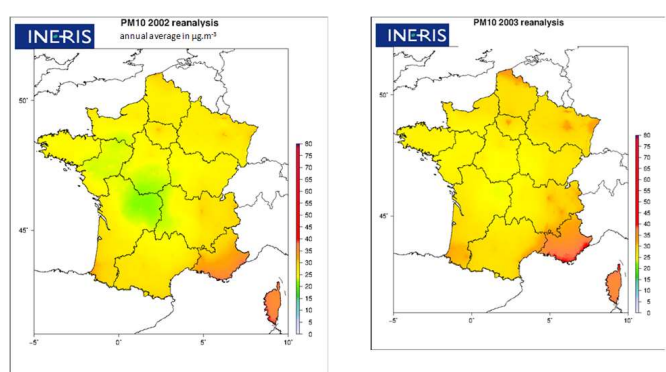

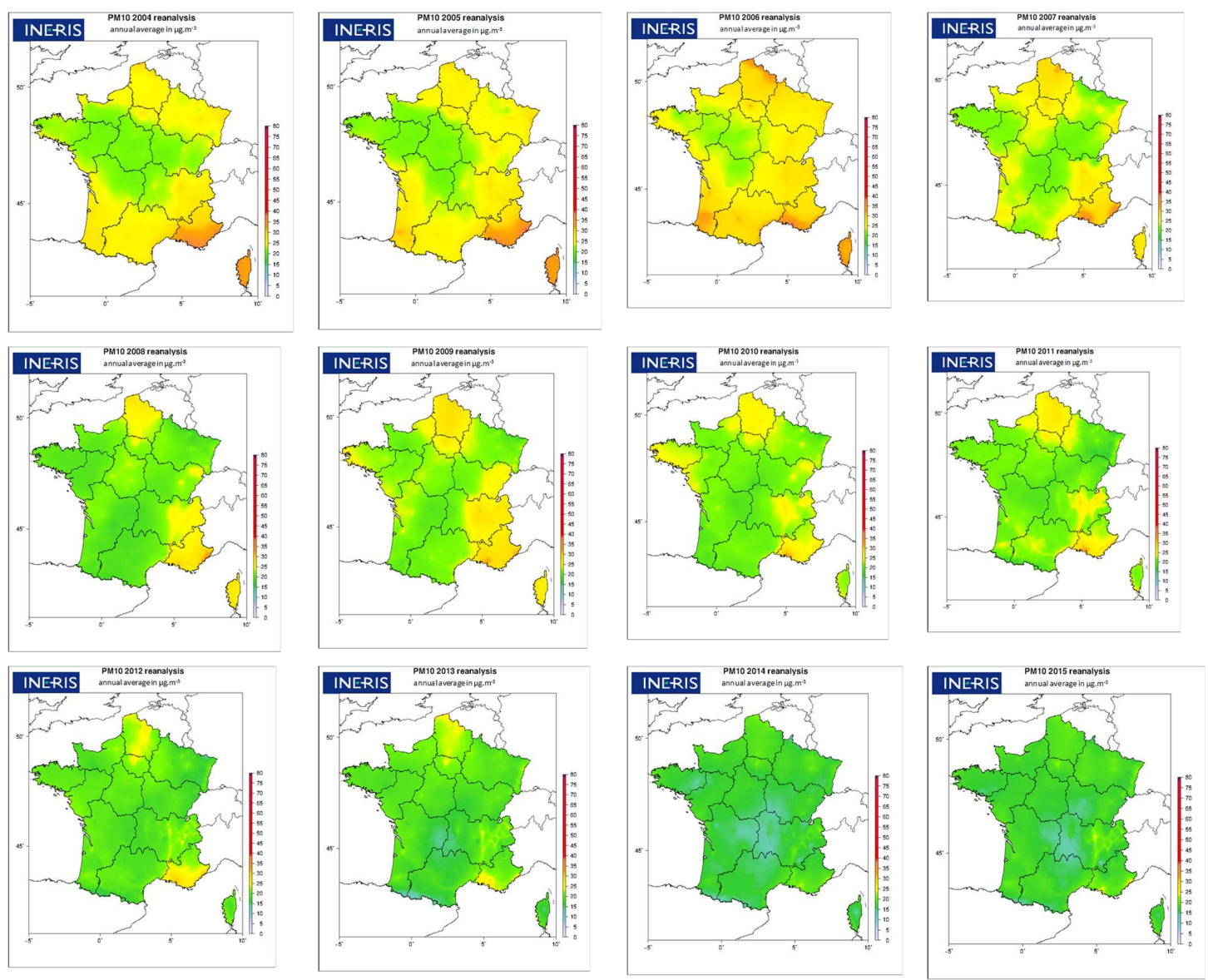

Figure 9: $\mathrm{PM}_{10}$ annual mean concentrations from 2000 to 2015 . Concentrations are obtained by combination between regional modelling and observations

Annual mean $\mathrm{PM}_{10}$ concentration maps are shown in Figure 9. for the period 2000-2015. The grid resolution (around 4km) allows to see patterns such as interconnected cities, especially in the latest years for which large inter-regional concentrations

5 patterns decrease. The impact of meteorological conditions can also be seen through the inter annual variability. For example, the heatwave year 2003 is associated with higher level of $\mathrm{PM}_{10}$ due to higher formation of secondary aerosols.

Figure 10 shows the mapped trends in annual mean $\mathrm{PM}_{10}$ expressed as Sen-Theil regression slope in $\mu \mathrm{g} . \mathrm{m}^{-3}$ per year and calculated over the period 2000-2015. 
https://doi.org/10.5194/essd-2021-182

Preprint. Discussion started: 13 July 2021

(c) Author(s) 2021. CC BY 4.0 License.

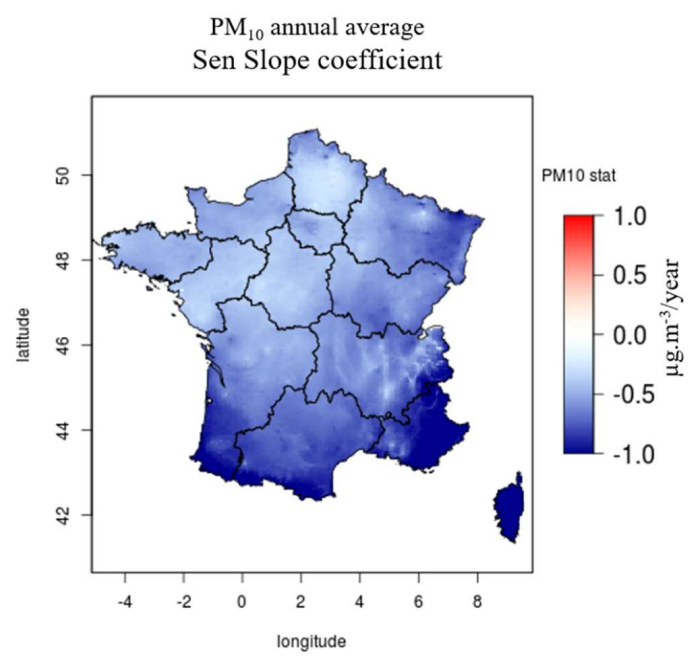

Figure 10: Trends in $\mathrm{PM}_{10}$ annual mean concentration. Sen slope coefficient ( $\mu \mathrm{g} . \mathrm{m}^{-3} / \mathrm{year}$ ) calculated over the period 2000-2015

There is a clear negative trend in $\mathrm{PM}_{10}$ annual mean concentrations over years for all regions. but the highest ones are observed

5 over regions with the highest $\mathrm{PM}_{10}$ concentrations at the beginning of the period: the South of France (East and West), the Auvergne-Rhône-Alpes region, the East (Grand-Est) and the extreme north of France. On average, a country-averaged negative trends in $\mathrm{PM}_{10}$ concentrations of $-0.8 \mu \mathrm{g} \cdot \mathrm{m}^{-3}$ per year is estimated over the period 2000-2015 (spatial average of the trend calculated over each grid). This trend is statistically significant with a narrow 95\%-confidence interval ([-0.5;-1.09]) that does not include zero (see Table 3). This significant decrease is the result of the reduction of primary pollutant over these 16 years

10 in response to emission reduction. From 2000 to 2015, primary $\mathrm{PM}_{10}$ emissions over France have been reduced by $39 \%$, as well as emission of $\mathrm{PM}_{10}$ precursors such as NOx emissions (-56 \%) and SOx emissions (-87\%) (data calculated by the CITEPA and extracted from the 2015 French national air quality report https://www.statistiques.developpementdurable.gouv.fr/sites/default/files/2018-10/datalab-bilan-de-la-qualite-de-l-air-en-france-en-2015-octobre-2016-c.pdf). 
3.1.2. $\mathbf{P M}_{2.5}$
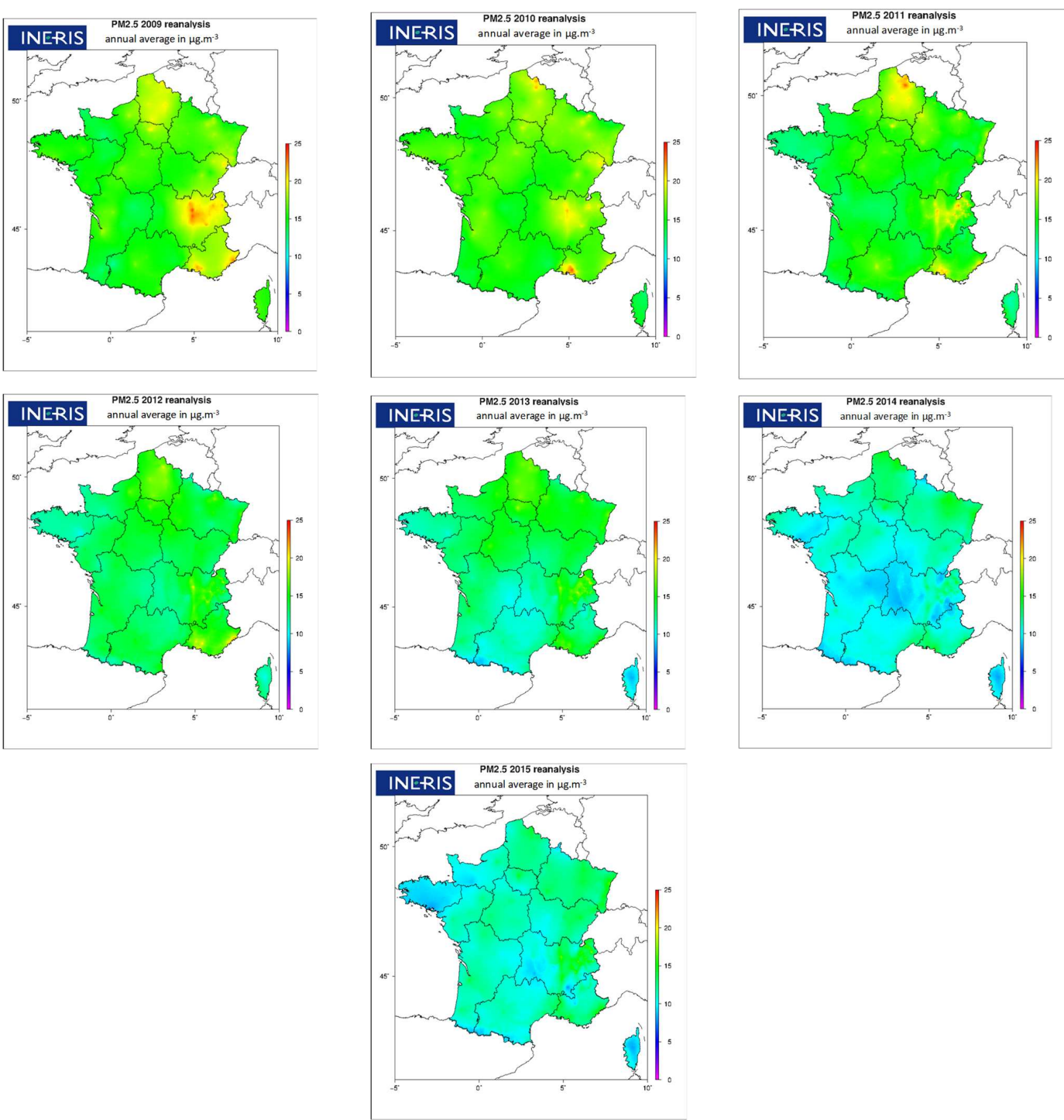

Figure 11: $\mathrm{PM}_{2.5}$ annual mean concentrations from 2009 to 2015. Concentrations are obtained by combination between regional modelling and observations. 
https://doi.org/10.5194/essd-2021-182

Preprint. Discussion started: 13 July 2021

(c) Author(s) 2021. CC BY 4.0 License.

The $\mathrm{PM}_{2.5}$ highest values are observed at the beginning of the period and are more concentrated over the main sources regions than $\mathrm{PM}_{10}$. Important reductions of yearly mean background concentrations are observed over years. Sen slopes coefficients calculated for the yearly mean $\mathrm{PM}_{2.5}$ (Figure 12.) over the period show negative trends over the entire territory, more pronounced over the South-East region, the Auvergne-Rhone-Alpes one, the North of France and Brittany. A country-averaged

5 negative trend of $-0.87 \mu \mathrm{g} \cdot \mathrm{m}^{-3}$ per year is calculated, again with statistical significance ( $95 \%$ interval of $[-0.48 ;-1.41]$ that does not contain zero). As for $\mathrm{PM}_{10}$, this negative trend is associated to the reduction in primary $\mathrm{PM}_{2.5}$ emissions and in $\mathrm{PM}_{2.5}$ precursors emissions (SOx, NOx and VOC).

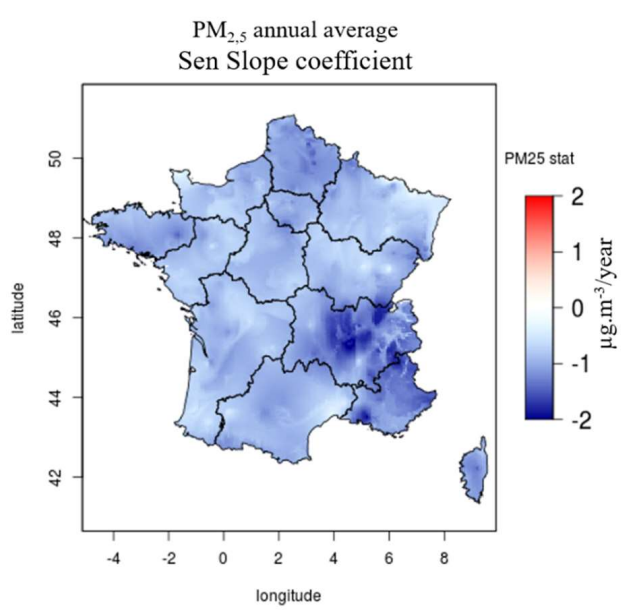

Figure 12: trends in $\mathbf{P M}_{2.5}$ annual mean concentration. Sen slope coefficients ( $\left.\mu \mathrm{g} . \mathrm{m}^{-3} / \mathrm{year}\right)$ calculated over the period 2009-2015.

\subsubsection{Ozone}
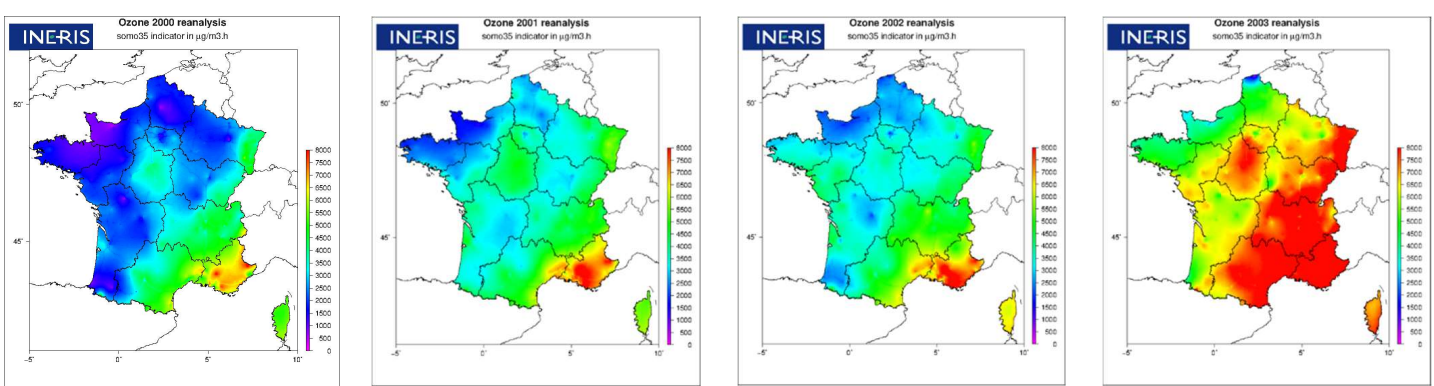

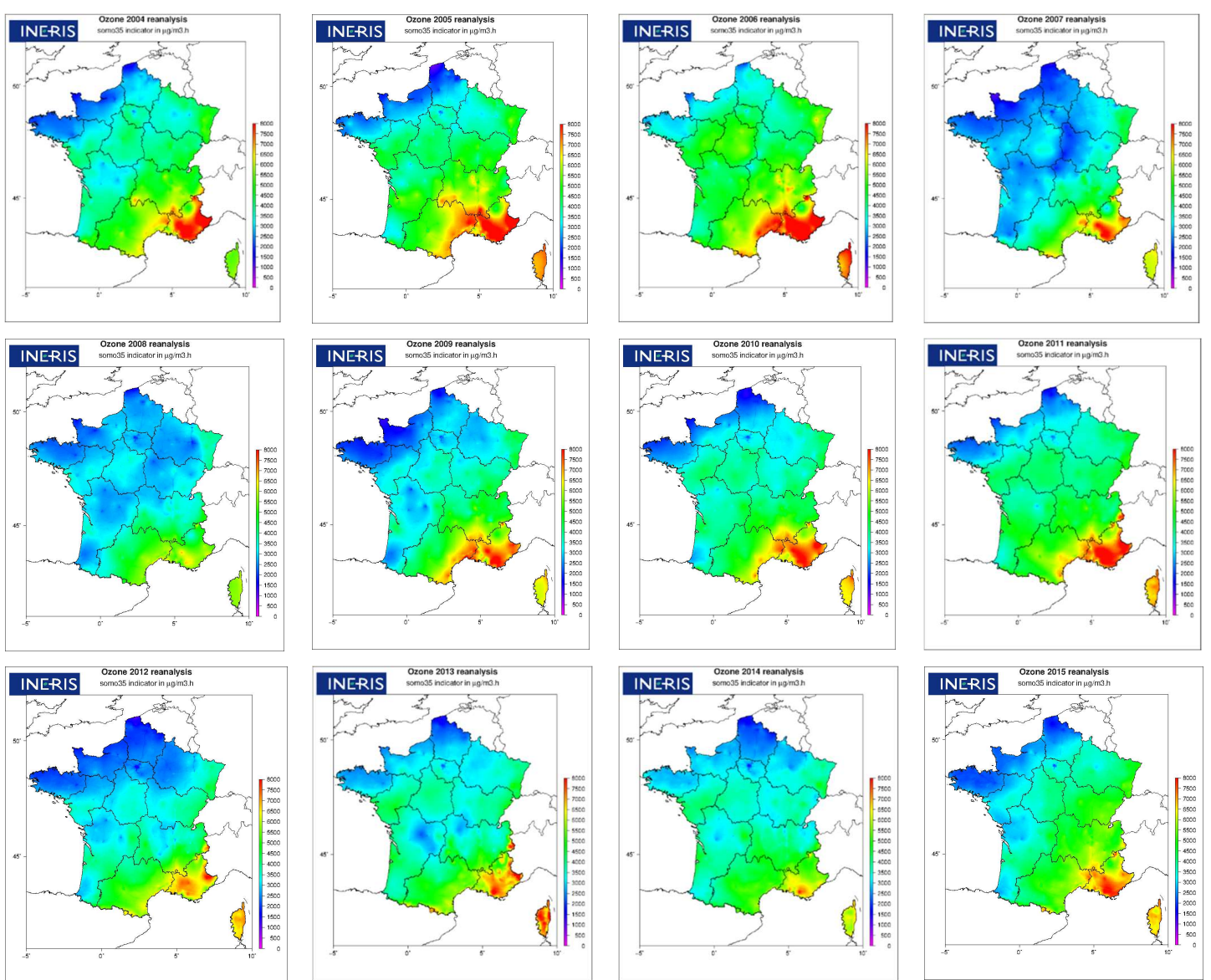

Figure 13: SOMO35 indicator for the period 2000 to 2015. Ozone concentrations are obtained by combination between regional modelling and observations.

The SOMO35 indicator shows a strong inter-annual variability. $\mathrm{O}_{3}$ is a photochemical pollutant produced by secondary reactions in presence of NOx, VOC and sunlight. The hot year 2003 is noticeable with very high SOMO35 over almost all the

5 territory. For every year the largest SOMO35 are found in the south-east of France and to a lesser extent over the Alsace region. Trends of SOMO35, annual mean $\mathrm{O}_{3}$ and AOT40 over years are represented in Figure 14. for the 2000-2015 period. 
a) Yearly mean concentrations

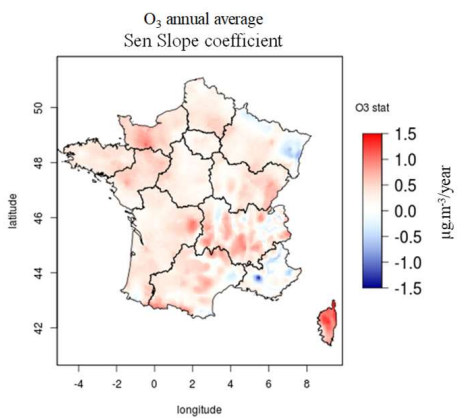

b) $\mathrm{SOMO} 35$

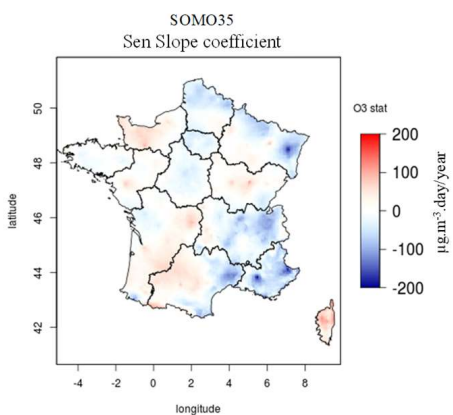

c) $\mathrm{AOT} 40$

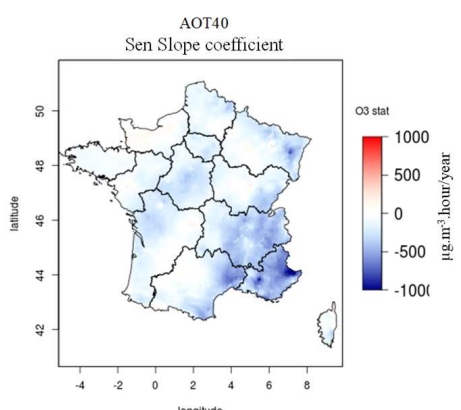

Figure 14: Trends in annual mean $O_{3}$ concentrations in $\mu \mathrm{g} \cdot \mathrm{m}^{-3} \cdot \mathrm{year}^{-1}$ (a), SOMO35 in $\mu \mathrm{g} \cdot \mathrm{m}^{-3}$.day.year ${ }^{-1}$ (b) and AOT40 in $\mu \mathrm{g} \cdot \mathrm{m}^{-}$ ${ }^{3}$.hour.year ${ }^{-1}$ (c) indicators. Sen slope are calculated over the period 2000-2015.

For the $\mathrm{O}_{3}$ average annual concentration, small positive trends are found over France. Two exceptions are the south-east

(PACA region) and the Grand-Est region (East of France), i.e the regions with the highest $\mathrm{O}_{3}$ concentrations, showing negative trends. Averaging over France, this leads to a positive trend of $0.32 \mu \mathrm{g} . \mathrm{m}^{-3}$.year ${ }^{-1}$. Both negative and positive trends are significant according to the mapped $95 \%$ confidence interval (not shown). SOMO35 and AOT40 indicators, that do not account for value lower than a threshold, show mostly negative trends. However these trends are not significant, according to the value of the mapped $95 \%$ confidence interval, that includes zero. These results are consistent with other European studies (EMEP 2016, Malherbe et al., 2017) that show an increase in background concentrations and a decrease in $\mathrm{O}_{3}$ peaks.

3.1.8. $\mathrm{NO}_{2}$
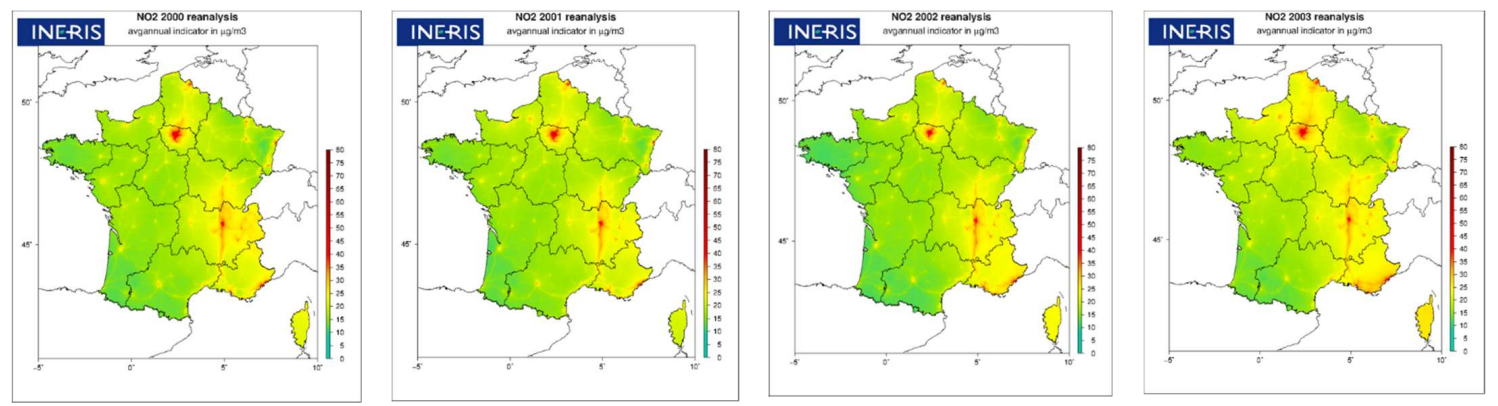

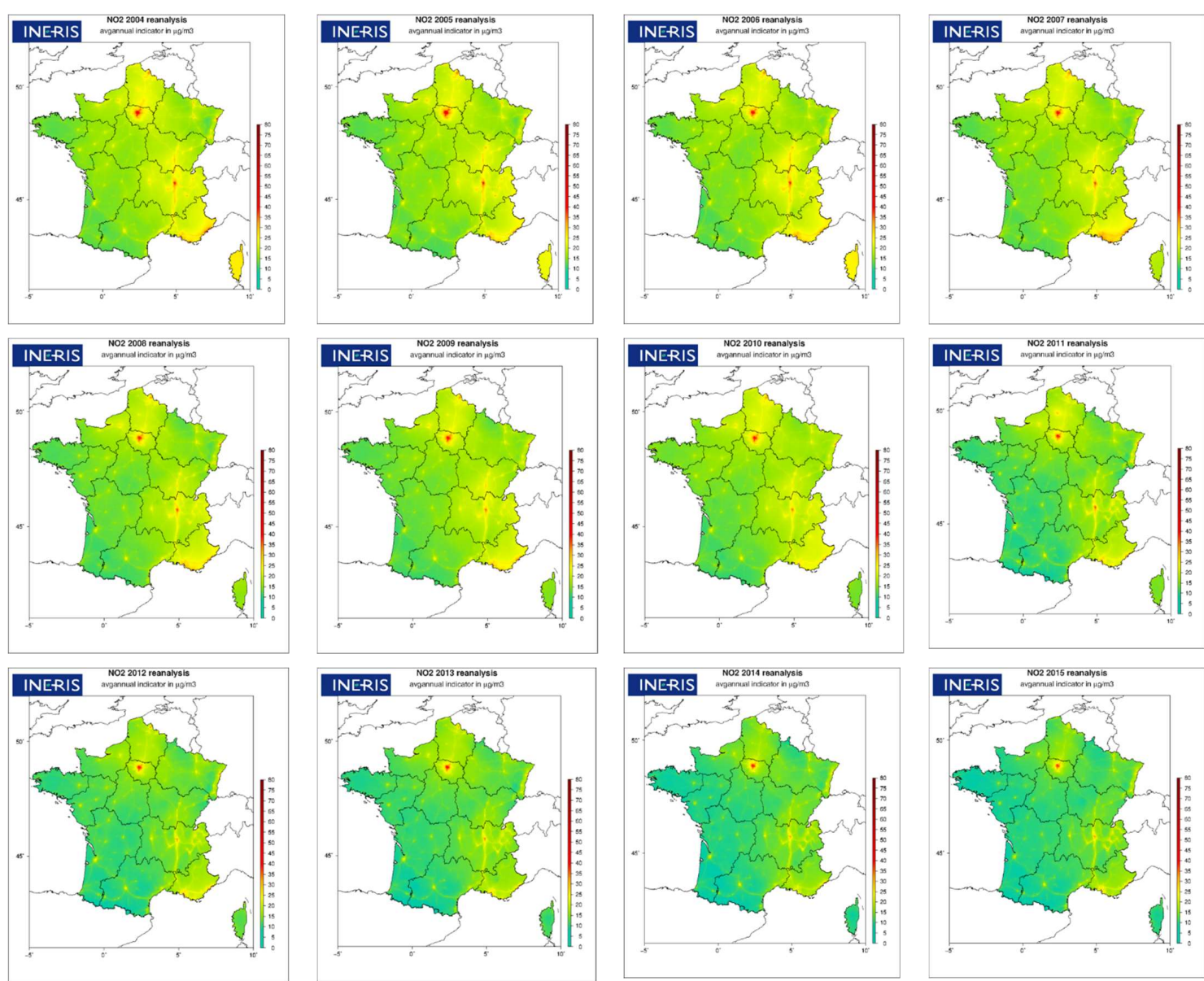

Figure 15: $\mathrm{NO}_{2}$ annual mean concentrations for the period 2000 to 2015 . $\mathrm{NO}_{2}$ concentrations are obtained by combination between regional modelling and observations.

$\mathrm{NO}_{2}$ is mainly emitted by road transports. All maps have the same pattern with cities and large interconnecting roads showing the highest $\mathrm{NO}_{2}$ concentrations. Trends over the 2000-2015 period are shown in Figure 15. Decreases in $\mathrm{NO}_{2}$ concentrations

5 are observed both on rural and urban regions over the entire territory. We remind however, that rural levels have been found to be overestimated with our approach (see 3.1.7). The decrease is larger where $\mathrm{NO}_{2}$ concentrations are important. As for $\mathrm{PM}_{2.5}$, these results highlight the combined benefit of large-scale emissions management policies that target emission sectors and locally-oriented policies. 


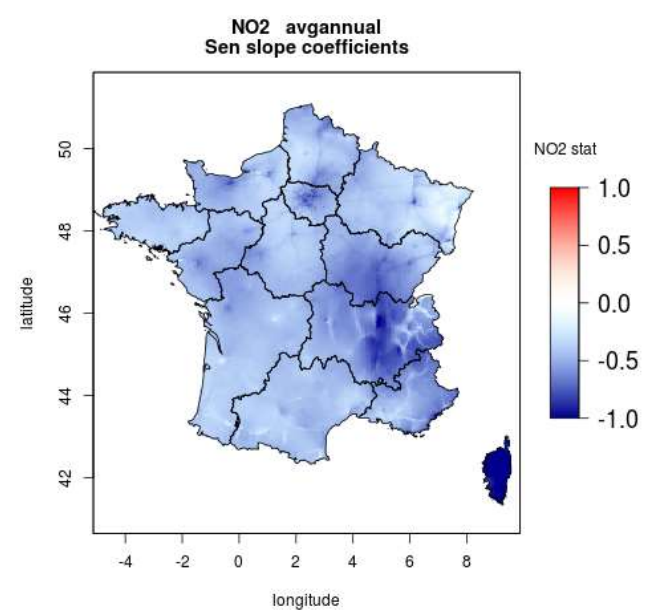

Figure 16: Trends in yearly mean $\mathrm{NO}_{2}$ concentrations. Sen slope coefficients $\left(\mu \mathrm{g} . \mathrm{m}^{-3} / \mathrm{year}\right)$ are calculated over the period 20002015.

On average, a significant negative trend of $-0.46 \mu \mathrm{g} \cdot \mathrm{m}^{-3}$ is calculated over France, with a narrow $95 \%$ confidence interval (see 5 Table 3).

\subsection{Exposure trends}

Population-weighted annual average concentrations are good estimates of population exposure, because they give greater weight to the air pollution found where most people live. Here, the country-averaged population weighted concentrations of $\mathrm{NO}_{2}, \mathrm{PM}_{2.5}$ and SOMO35 (3 health impact indicators) are calculated for each evaluated year, from the hourly corrected mapped data over France. For one pollutant, it is obtained by summing over all country grids, the result of the multiplication of the concentration per the population in the grid, and then divided it by the total population of the country. The population database used in this study is the national LCSQA population database (Létinois et al., 2014) established for year 2015. It is based on detailed files from the French finance department with information at a building level. It is important to notice that the French

15 population used here did not vary with years. This population increased by about $10 \%$ between 2000 and 2015 . However, if we considered that the demographic evolution was homogeneous over the country (urban/rural proportion only increased by about $2.5 \%$ in France over the same period), the country-averaged population weighted concentration should be the same whatever the year of the population database. 


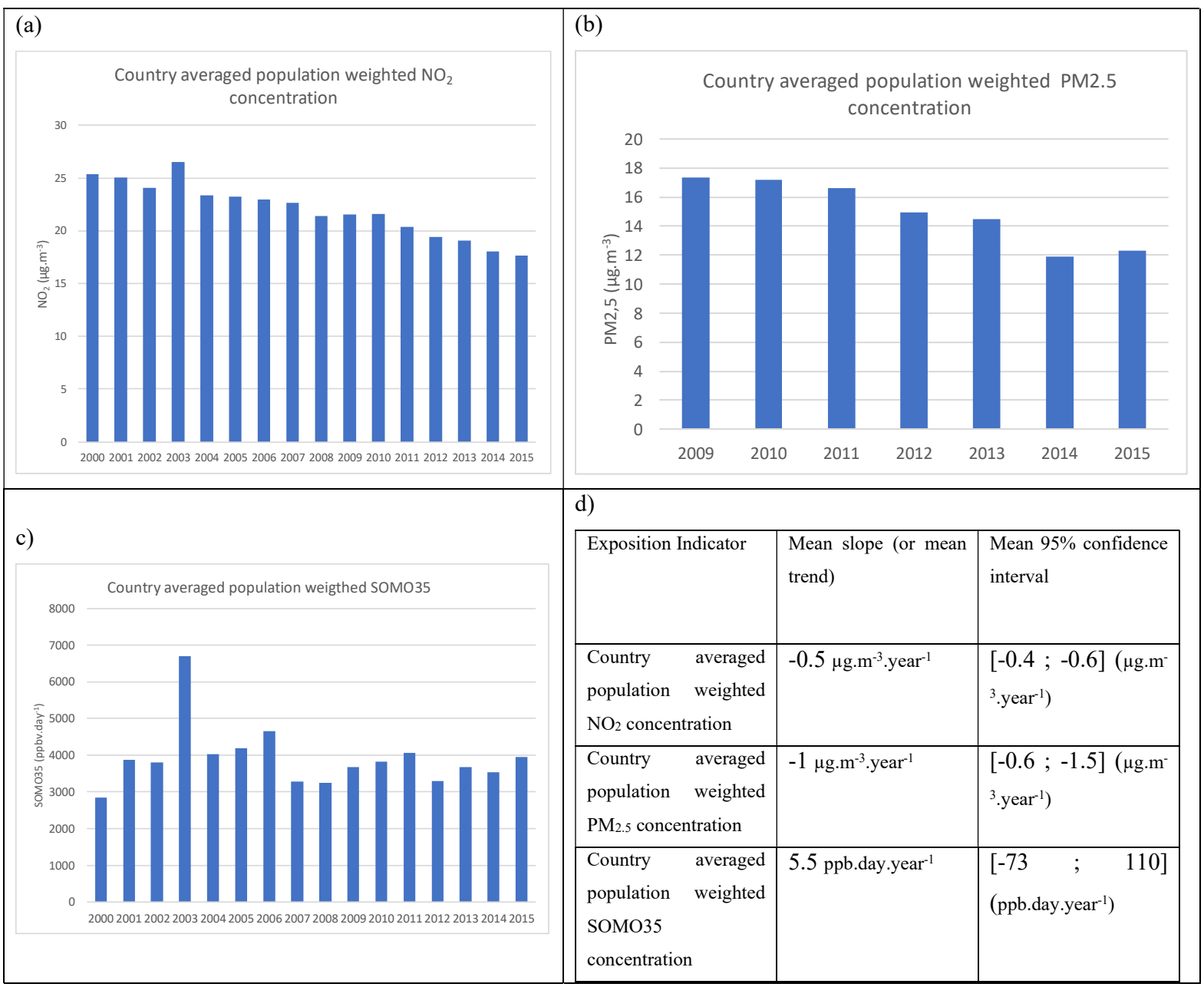

Figure 17: Yearly evolution of the country averaged population weighted of (a) $\mathrm{NO}_{2}$ concentration (b) $\mathrm{PM}_{2.5}$ concentration c) SOMO35. Trends and $95 \%$ confidence intervals are calculated (d).

As for the concentrations, a very clear trend is observed on the country averaged population weighted $\mathrm{NO}_{2}$ with a negative trend of $-0.5 \mu \mathrm{g} . \mathrm{m}^{-3}$.year ${ }^{-1}$ (with a narrow $95 \%$ confidence interval: [-0.4,-0.6]) leading to a reduction of about $30 \%$ in 16

5 years. A negative trend of $-1 \mu \mathrm{g} \cdot \mathrm{m}^{-3} \cdot \mathrm{year}^{-1}$ is also clearly calculated for $\mathrm{PM}_{2.5}(95 \%$-confidence interval: [-0.6,-1.5]) over the period 2009-2015, a reduction of about $31 \%$ in 7 years. On the contrary, there is no clear trend for the SOMO35 indicator over the period 2000-2015. 
When the abovementioned indicators are multiplied by the total population (to obtain the total exposure, i.e the sum of the population weighted over a country), the results indicators are those used to calculate health impact assessment based on doseresponse functions, as suggested by the WHO review of "Health Risks of Air Pollution in Europe" (WHO 2013), described in Holland (2014 a and b). Exposure to SOMO35, anthropic $\mathrm{PM}_{2.5}$ and $\mathrm{NO}_{2}$ (with or without threshold depending on the health

5 impact indicator) contribute both to morbidity and mortality impacts. For example, over France, they have been used in the PREPA-evaluation study for which about fifty political measures to be applied over France have been evaluated and classified over different criteria, such as air quality impact, health impact and cost-benefit assessment (Schucht et al., 2018). At constant population evolution, the trends are similar between both indicators (total exposure and population weighted average concentration). However the evolution in population (even when homogeneous over the territory) does impact the total

10 population exposure. Therefore, we expected a reduced impact on health impact assessment compared to those on population weighted concentrations.

\section{Data availability}

Mapped regulatory indicators and exposure data for all 15 years and the 4 pollutants described here are available on a zenodo 15 repository under the Netcdf format (version $\mathrm{n}^{\circ} 4$ ) and csv format for data at the municipal or regional level. The DOI link for the dataset is http://doi.org/10.5281/zenodo.5043645 (Real et al., 2021). It is also available through a web-based map library (https://www.ineris.fr/fr/recherche-appui/risques-chroniques/mesure-prevision-qualite-air/20-ans-evolutionqualite-air). The web-based map library is intended to be updated annually.

\section{Conclusion}

20 A 16-year datasets of mapped air pollution concentrations and indicators over France have been constructed using a data fusion technique (kriging) that combines measurement from background surface monitoring station and modelling from the regional model CHIMERE. The resulting data are hourly concentrations at a resolution of about $4 \mathrm{~km}$ horizontal resolution over France for the period 2000-2015 (more restricted period for $\mathrm{PM}_{2.5}$ and hourly-based $\mathrm{PM}_{10}$ indicators).

The kriging technique implemented combined external drift kriging for $\mathrm{NO}_{2}$ and $\mathrm{O}_{3}$ and co-kriging with external drift for 25 particulate matter, allowing $\mathrm{PM}_{2.5}$ estimation to benefit from the higher density of $\mathrm{PM}_{10}$ monitoring stations. The overall datasets have been evaluated over years using a cross-validation process that account for the incorporation of measurements in the correction process by withholding one datapoint before calculating the score. Concentrations of both rural and background urban stations are very well reproduced for $\mathrm{O}_{3}, \mathrm{PM}_{10}$ and $\mathrm{PM}_{2.5}$ with low mean biases, RMSE and good correlations. The same behaviour is found over background urban $\mathrm{NO}_{2}$ stations, while rural $\mathrm{NO}_{2}$ concentrations are 30 systematically overestimated. The performance of the dataset to reproduce measurement was generally correlated with the 
number of stations over the domain, up to a threshold where adding station do not seem to increase these performances. This threshold number was dependant on the pollutant, higher for pollutant showing high spatial gradient (i.e $\mathrm{NO}_{2}$ that has a shorter lifetime).

Some of the produced mapped concentrations and indicators are detailed in the paper, and yearly trends are calculated. Clear 5 and significative negative trends are calculated over the whole period for $\mathrm{PM}_{10}, \mathrm{PM}_{2.5}$ and $\mathrm{NO}_{2}$ yearly mean concentrations. They reflect the reductions in precursor emissions operated in Europe since the 90 's. $\mathrm{O}_{3}$ trends over these 16 years are less significant. In general, $\mathrm{O}_{3}$ background level is increasing, mainly due to large-scale pollution and $\mathrm{O}_{3}$ high levels (peaks) are decreasing due to local $\mathrm{O}_{3}$ precursors emissions reduction. This leads to a positive trend for $\mathrm{O}_{3}$ mean annual average concentration over most of France, but a small negative trend is also found over the regions showing the higher $\mathrm{O}_{3}$ levels

10 (south-east and east). No significant trends are calculated for the two $\mathrm{O}_{3}$ indicators detailed here (SOMO35 and AOT40). Population exposition is also calculated over France with the same trends. The country averaged population weight of $\mathrm{NO}_{2}$ and $\mathrm{PM}_{2.5}$ is decreasing by respectively $30 \%$ in 16 years and $31 \%$ in 7 years. No clear trend is found for SOMO35 population weight.

\section{Author contribution}

Data kriging, results evaluation by cross-validation process and maps and graph production for the papers were performed by E. Real. The CHIMERE modelling concentration data over the period 2000-2015 were produced by F. Couvidat. Software developments for the kriging and cross-validation methods were provided by A. Ung and L. Malherbe. The web-based map library used to store and visualised the data has been developed by B. Raux. The all work has been supervised and conceptualized by A. Colette. The manuscript draft has been mainly written by E. Real with contribution of all co-authors.

\section{Competing interests}

The authors declare that they have no conflict of interest.

\section{Acknowledgements:}

This work was supported by the French Ministry in Charge of Ecology. Modelling concentration data from the XENAIR program. Part of the simulations were carried out in the XENAIR project funded by the ARC Foundation for Cancer Research. 


\section{References}

Amann, M., Bertok, I., Borken-Kleefeld, J., Cofala, J., Heyes, C., Höglund-Isaksson, L., Klimont Z., Nguyen B., Posch M.,Rafaj P., Sandler R., Schöpp W., Wagner F., Winiwarter W. ,Cost-effective control of air quality and greenhouse gases in Europe: Modeling and policy applications. Environmental Modelling \& Software, 26(12), 1489-1501, 2011

Beauchamp, M., "An adaptation of the covariance modeling for large scale geostatistics estimation in Air Quality." Conférence Spatial Statistics" Emerging Patterns". 2015a

Beauchamp, M., LCSQA notes, https://www.lcsqa.org/fr/rapport/2015/ineris/synthese-developpements-recents-matiere-

10 cartes-analysees-resultats-modelisation, 2015b

Beauchamp, M., de Fouquet, C., Malherbe, L., Dealing with non-stationarity through explanatory variables in kriging-based air quality maps, Spatial statistics, Volume 22, Part 1, November 2017, Pages 18-46. 2017

15 Benmerad, M., Slama, R., Botturi, K., Claustre, J., Roux, A., Sage, E., Reynaud-Gaubert, M., Gomez, M., Kessler, R., Brugière, O., Mornex, J-F., Mussot, S., Dahan, M., Boussaud, V., Danner-Boucher, I., Dromer, C., Knoop, C., Auffray, A., Lepeule, J., Malherbe, L., Meleux, F., Nicod, L., Magnan, A., Pison, C., Siroux, V., Chronic effects of air pollution on lung function after lung transplantation in the Systems prediction of Chronic Lung Allograft Dysfunction (SysCLAD) study, European Respiratory Journal, vol.49, No 1, p. 1600206, 2017

Bessagnet B., Malherbe L., Aymoz G. : Bilan de la première année de mesure des PM10 ajustées en France et évaluation des outils de modélisation. Rapport LCSQA, www.lcsqa.org, 2008

Colette, A., Andersson, C., Manders, A., Mar, K., Mircea, M., Pay, M-T., ... Wind, P. A., EURODELTA-Trends, a multi25 model experiment of air quality hindcast in Europe over 1990-2010. Geoscientific Model Development, 10(9), 3255-3276, 2017

Couvidat, F., Bessagnet, B., Garcia-Vivanco, M., Real, E., Menut, L., and Colette, A.: Development of an inorganic and organic aerosol model (CHIMERE 2017 $\beta$ v1.0): seasonal and spatial evaluation over Europe, Geosci. Model Dev., 11, 165-

30 194, https://doi.org/10.5194/gmd-11-165-2018, 2018

Denier van der Gon, H. A. C., Bergström, R., Fountoukis, C., Johansson, C., Pandis, S. N., Simpson, D., and Visschedijk, A. J. H.: Particulate emissions from residential wood combustion in Europe - revised estimates and an evaluation, Atmos. Chem. Phys., 15, 6503-6519, https://doi.org/10.5194/acp-15-6503-2015, 2015

35 EEA: Air Quality in Europe - 2018 Report, Copenhagen, 2018

EMEP, 2016, Air pollution trends in the EMEP region between 1990 and 2012, joint TFMM/CCC/MSC-E and MSC-W report, CCC-Report 1/2016, European Monitoring and Evaluation Programme, Norway (http://www.nilu.no/projects/ccc/reports/cccr1-2016.pdf), accessed 19 July 2019.

40 Holland, M.,Implementation of the HRAPIE Recommendations for European Air Pollution CBA work. Health Impact Assessment and Cost Benefit Analysis. EMRC, 2014a

Holland, M., Cost-benefit Analysis of Final Policy Scenarios for the EU Clean Air Package, Version 2, Corresponding to IIASA TSAP Report 11, Version 1, EMRC, 2014b

Honoré C., Menut L., Bessagnet B., Meleux F., Rouïl L., Vautard R., Poisson N. and Peuch V.H., Chapter 3.4 PREV'AIR: A platform for air quality monitoring and forecasting, Developments in Environmental Science, Volume 6, Pages 293-300, 2007 
IHME, I. for H.M. and E, The Global Burden of Disease_Generating Evidence, Guiding Poliy - European Union and Free Trade Association.Pdf, 2013

5 Létinois, L., Méthodologie de répartition spatiale de la population, rapport LCSQA, 2014

Mailler, S., Menut, L., Khvorostyanov, D., Valari, M., Couvidat, F., Siour, G., Turquety, S., Briant, R., Tuccella, P., Bessagnet, B., Letinois, L., Markakis, K., Meleux, F. and Colette, A., CHIMERE-2017: from urban to hemispheric chemistry-transport modeling, 2017

Malherbe, L. and Ung, A., Travaux relatifs à la plate-forme nationale de modélisation PREV'AIR : Réalisation de cartes

10 analysées d'ozone (2/2), rapport LCSQA, 2009

Malherbe L., Beauchamp M., Bourin A, and Sauvage S., Analyse de tendances nationales en matière de qualité de l'air, Rapport final LCSQA, 2017

15 Real E., Couvidat F., Ung A., Malherbe L., Raux B., \& Colette A.. (2021). Historical reconstruction of background air pollution over France for 2000-2015 [Data set]. Zenodo. http://doi.org/10.5281/zenodo.5043645

Rivoirard, J., Romary, T., Continuity for kriging with moving neighborhood. Mathematical Geosciences, Springer Verlag, 43 (4), pp.469-481, 2011

Rouil, L., Honore, C., Vautard, R., Beekmann, M., Bessagnet, B., Malherbe, L., . Beekmann L., Bessagnet B., Malherbe L., Meleux F.,Dufour A., Elichegaray C., Flaud J-M., Menut L., Martin D., Peuch A., Peuch V-H, and Poisson N, PREV'AIR: an operational forecasting and mapping system for air quality in Europe. Bulletin of the American Meteorological Society, 90(1), 73-84, 2009

Schucht, S., Real, E., Couvidat, F., Rouil, L., Brignon, J. M., Allemand, N., Le Clercq G. and Fayolle, D., Economic analysis of health impacts in the National Air Pollution Control Programme. Environnement, Risques \& Santé, 17(4), 393-400, 2018

Skamarock, W. C., Klemp, J. B., Dudhia, J., Gill, D. O., Barker, D. M., Wang, W., \& Powers, J. G.,A description of the Advanced Research WRF version 3. NCAR Technical note-475+ STR, 2008

WHO, Health risks of air pollution in Europe - HRAPIE - Summary of recommendations for question D5 on "Identification of concentration-response functions" for cost-effectiveness analysis. In: health., W.E.C.f.e.a. (Ed.)., 2013 